\title{
Polymorphism of the Prolactin Gene in Egyptian Duck Breeds
}

\author{
Nevien M. Sabry ${ }^{1}$, Dalia M. Mabrouk ${ }^{1}$, Mohamed A. Abdelhafez ${ }^{1}$, Esteftah M. El-Komy ${ }^{2}$ and Karima F. Mahrous ${ }^{1 *}$ \\ ${ }^{1}$ Cell Biology Department, Genetic Engineering \& Biotechnology Research Division, National Research Centre, Giza 12622, Egypt \\ ${ }^{2}$ Animal Production, Genetic Engineering \& Biotechnology Research Division, National Research Centre, Giza 12622, Egypt
}

*Corresponding author's Email: 1_fathy@yahoo.com; ORCID: 0000-0002-1662-1034

Received: 18 Oct. 2020

Accepted: 07 Dec. 2020

\begin{abstract}
In avian, the prolactin hormone triggers and regulates ovarian follicle development. This study aims to detect the Prolactin $(P R L)$ gene polymorphisms (exons 1and5) in four Egyptian duck breeds, namely Campbell, Moulard, Muscovy, and Pekin using PCR-RFLP technique and sequence analysis. It also investigated the association of this gene with egg production, egg weight, and body weight. The present results revealed that $P R L$ gene exon 1 and part of intron 1 showed two alleles A and B (polymorphic) in each of Campbell and Moulard, however, Muscovy and Pekin had only one allele (monomorphic). The allele A was more dominant with frequencies of $0.70,0.60$, and 1.00, compared to the allele B (0.30, 0.40, and 0.00) for Campbell, Moulard, and Muscovy, respectively. For Pekin, the allele B only appeared with the frequency of 1.0. Ducks with the high frequency of allele A were superior at egg weight, compared to others. Furthermore, for PRL gene exon 5, there were two alleles $\mathrm{G}$ and $\mathrm{C}$ (polymorphic) in Campbell, Moulard, and Muscovy, however, Pekin had only one allele (monomorphic). The allele G was more dominant $(0.15,0.74,0.0$, and 0.84$)$ than the allele $C(0.85,0.26,1.0$, and 0.15$)$ for Campbell, Moulard, Pekin, and Muscovy, respectively. Ducks having a high frequency of allele $\mathrm{C}$ were superior at egg production. Furthermore, there were many single nucleotide polymorphisms (SNPs) in the sequences in all breeds. The utmost ones exist at the

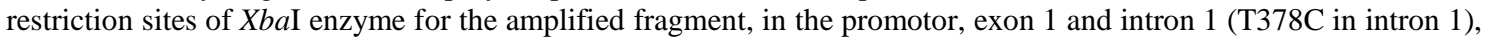
and DraI enzyme for that in exon 5 (A5871G in exon 5).
\end{abstract}

Keywords: Duck, Genetic polymorphism, Genotyping, Prolactin gene

\section{INTRODUCTION}

Meat and eggs of ducks have a high nutritional value for humans. Ducks are foremost raised in small rural farms to produce eggs and meat to improve economic livelihood. Ducks have great economic importance to many countries (Narhari, 2009). The Pekin duck (Anas platyrhynchos domestica), Muscovy duck (Cairina moschata), and Moulard ducks (crossing between Muscovy and Pekin duck), are the main duck species that are used globally to produce meat of ducks (Baeza, 2006). The Muscovy duck (Cairina moschata) meat has a distinct taste, with low calories, so it has global economic importance (Veeramani et al., 2016). The Muscovy and Moulard are characterized by lower fatness and higher meat production as compared by Pekin ducks (Wawro et al., 2004). The Campbell duck (Anas platyrhynchos) is a high egg-production breed. Moreover, the nutritional value of duck eggs is higher than chicken ones, in its mineral salts, vitamins, and amino acids (Sadar et al., 2014).
Traditional breeding approaches of selection and crossbreeding have improved the productivity of duck and devised new hybrids, while improvement using this method was slow (Asiamah et al., 2019). Duck productivity was increased using modern methods of molecular genetics, by identifying candidate genes associated with quantitative traits to improve productive traits and enhance breeding programs (Basumatary et al., 2019). One of the utmost serious problems in farming ducks is the low productivity and quality of production. Therefore, their genetic improvement aims to increase productivity, improve product quality and elevate economic value (Chang et al., 2012). Genetic improvement programs using traditional and modern methods for meat-type ducks have successfully enhanced their productive performance. In Pekin ducks, the genetically improved type for higher meat production reached to $3.2 \mathrm{~kg}$ at seven weeks, while unimproved duck production reached to $1.7 \mathrm{~kg}$ at 11 weeks of age (Zeng et al., 2016). 
Prolactin hormone gene $(P R L)$ is a single-chain polypeptide belongs to the family of growth hormone genes, and synthesized by the anterior pituitary gland of poultry (Wang et al., 2011). The size of duck prolactin gene is $1000 \mathrm{bp}$ in size and consists of five exons and four introns encoding 229 amino acids. As the chicken $P R L$ gene was cloned and sequenced (Watahiki et al., 1989), a bulk of studies have targeting this gene polymorphism (Xu et al., 2015; Shamsalddini et al., 2016; Li et al., 2017). In recent years, polymorphisms in the $P R L$ gene have been associated with egg production in hens (Sarvestani et al., 2013; Kulibaba, 2015; Tempfli et al., 2015; Mohamed et al., 2017; Yadav et al., 2018; Bai et al., 2019; Basumatary et al., 2019).

Identifying single nucleotide polymorphisms (SNPs) in candidate genes and their association with egg laying traits is an important technique used to enhance the avian genetics (Feng et al., 2018). Therefore, the present study used four Egyptian duck breeds; Moulard, Campbell, Pekin and Muscovy ducks to screen polymorphism of the duck $P R L$ gene. Identifying of such SNPs can be employed as genetic markers for selection of genetically superior ducks to increase productivity.

\section{MATERIALSANDMETHODS}

\section{Ethical approval}

Permission for collecting the samples used in this work was received from the management of El-Nubaria farm, owned by National Research Centre that was included in this study. The samples were collected per standard sample collection procedures without any harm to animals.

\section{Animals}

The present study used a total of 60 healthy ducks, of four breeds; Campbell, Moulard, Muscovy and Pekin, raised in El-Nubaria experimental farm, owned by the National Research Centre-Giza-Egypt. 15 blood samples $(3 \mathrm{~mL})$ were aseptically collected from each breed, using EDTA $(0.5 \mathrm{M})$ as an anticoagulant.

\section{DNA Extraction}

Genomic DNA was isolated from whole blood of ducks using salting out method (Shokrzadeh and Mohammadpour, 2018), with minor modifications. Briefly, blood ( $3 \mathrm{ml}$ ) was mixed with cell lysis buffer (640 $\mathrm{mM}$ sucrose, $10 \mathrm{mM} \mathrm{MgCl} 2,20 \mathrm{mM}$ Tris-HCl, $2 \%$ Triton $100 \mathrm{X}$ ) and placed on ice for $30 \mathrm{~min}$ then centrifuged at $5000 \mathrm{rpm}$ for $15 \mathrm{~min}$ at $4^{\circ} \mathrm{C}$ and the supernatant was discarded. Nuclei lysis buffer (10 mM Tris-base, $400 \mathrm{mM}$ $\mathrm{NaCl}, 2 \mathrm{mM}$ EDTA) was added to the pellet and mixed with $20 \%$ Sodium Dodecyl Sulfate (SDS) and proteinase $\mathrm{K}$ then placed in a water bath at $55^{\circ} \mathrm{C}$ for two hours. $\mathrm{NaCl}$ (saturated) was added and centrifuged to separate a clear upper layer containing DNA. Only $30 \mu \mathrm{l}$ of the clear layer was transferred to a tube containing absolute ethanol to fish the DNA and dissolved in TE buffer $(10 \mathrm{mM}$ Tris$\mathrm{HCl}, 1 \mathrm{mM}$ EDTA) at $37^{\circ} \mathrm{C}$ for 2 hours. Purity and concentration of DNA were measured using Nano Drop ${ }^{\mathrm{TM}}$ 1000 Spectrophotometer (Thermo Fisher Scientific, USA). Extracted DNA was stored in $-20^{\circ} \mathrm{C}$ till usage.

\section{Polymerase Chain Reaction (PCR)}

The primers used were $F$ : 5'AAATTCCCTCTCACAG TTACA-3'; R: 5'GATGCAGAGACAAGTTTCACC-3' for PRL (intron 1) to produce a product of $417 \mathrm{bp}$ and $\mathrm{F}$ : 5'TGCAAACCATAAAAGAAAAGA-3'; R: 5'CAATGAAAAGTGGCAAAGCAA-3' for $P R L$ (exon 5) to produce a product of $400 \mathrm{bp}$. PCR amplification was carried out in a $25 \mu \mathrm{l}$ reaction volume, including $2 \mu \mathrm{l}$ genomic DNA (50 ng), $2.5 \mu \mathrm{L} 10 \mathrm{X}$ buffer, $2.5 \mathrm{mM}$ of deoxyribonucleotide triphosphates ( $\mathrm{dNTPs}$ ), $2.5 \mu \mathrm{l}$ of each primer $(10 \mathrm{pmol})$, and $0.5 \mu \mathrm{Taq}$ polymerase (Thermo-Fisher Scientific, USA). The PCR conditions were; $5 \mathrm{~min}$ at $94^{\circ} \mathrm{C}$, followed by 35 cycles of $1 \mathrm{~min}$ at $94^{\circ} \mathrm{C}, 30 \mathrm{sec}$ at the annealing temperature $54^{\circ} \mathrm{C}, 2 \mathrm{~min}$ at $72^{\circ} \mathrm{C}$ and a final extension of $7 \mathrm{~min}$ at $72^{\circ} \mathrm{C}$.

\section{(RFLP) \\ Restriction Fragment Length Polymorphism \\ Digestion of the PCR products was performed} overnight at $37^{\circ} \mathrm{C}$ in a final volume of $30 \mu \mathrm{l}$ with specific restriction enzymes (Thermo Fisher Scientific, USA); Xba I (5'T $\downarrow$ CTAGA-3') for PRL (Intron 1), and DraI (5 'TTTAAA $\downarrow 3$ ') for PRL (Exon 5). The RFLP reaction mixture composed of $10 \mu \mathrm{L}$ of PCR products, $1 \mathrm{U}$ of restriction enzymes, $2 \mu \mathrm{l}$ of buffer and 18 sterile $\mathrm{H}_{2} \mathrm{O}$. The digested products were run in $2.5 \%$ agarose gel and different genotypes were visualized under U.V. transilluminator and photographed using Gel documentation system.

\section{DNA Sequencing and Analysis}

The PCR products were purified using Gene JET Gel Extraction Kit (Thermo-Fisher Scientific, USA) according to the manufacture instructions. The purified PCR products were sequenced using an automated sequencing service (Macrogen, South Korea). Sequence analysis was 
performed via program BLAST/NCBI (National Center for Biotechnology Information.

http://www.ncbi.nlm.nih.gov/). Sequence alignment were accomplished by Clustal Omega version (1.2.4) (https://www.ebi.ac.uk/Tools/msa/clustalo), as described by (Larkin et al., 2007). The phylogenetic trees between the studied breeds, and other avian were done, using unweighted pair group method with arithmetic mean (UPGMA). To detect chromosomal localization of prolactin gene (exons 1 and 5) from Egyptian duck breeds in the duck genome, Anas platyrhynchos isolate PK-2015, IASCAAS_PekingDuck_PBH1.5, was used from NCBI.

\section{RESULTS}

In the current study, the DNA fragment (417 bp), covering the PRL gene promoter (220 bp), exon 1 (28 bp) and part of intron 1 (169 bp), was successfully PCR amplified, as well as the other fragment (400 bp), covers the coding region of $P R L$ gene exon 5 (192 bp), and part of intron 4 (137 bp, Figure 1a).

The XbaI/RFLP for PRL (the promoter, exon 1 and part of intron 1) revealed three fragments; non-cut fragment (417 bp) or homozygous genotype (AA), cut fragments (356 bp and $61 \mathrm{bp}$ ) or homozygotes (BB) [61 bp band is not visible because it is too short], and the combined fragments (417 bp, $356 \mathrm{bp}$ and $61 \mathrm{bp}$ ) or heterozygotes (AB Figure 1b). As illustrated in Table 1, both Campbell and Moulard breeds are polymorphic resulted two alleles (A and $\mathrm{B}$ ). However, Muscovy (A) and Pekin (B) were monomorphic resulted one allele. The allele A frequency was much higher than allele $B$ in the four breeds. The results revealed that the four investigated duck breeds, PRL gene exon 1 and part of intron 1, had two alleles ( $\mathrm{A}$ and $\mathrm{B}$ ) and three genotypes $\mathrm{AA}, \mathrm{AB}, \mathrm{BB}$, ducks with higher frequency of allele $\mathrm{A}$ superior at egg weight, at 10-weeks-old body weight compared to other duck breeds (Table 1).
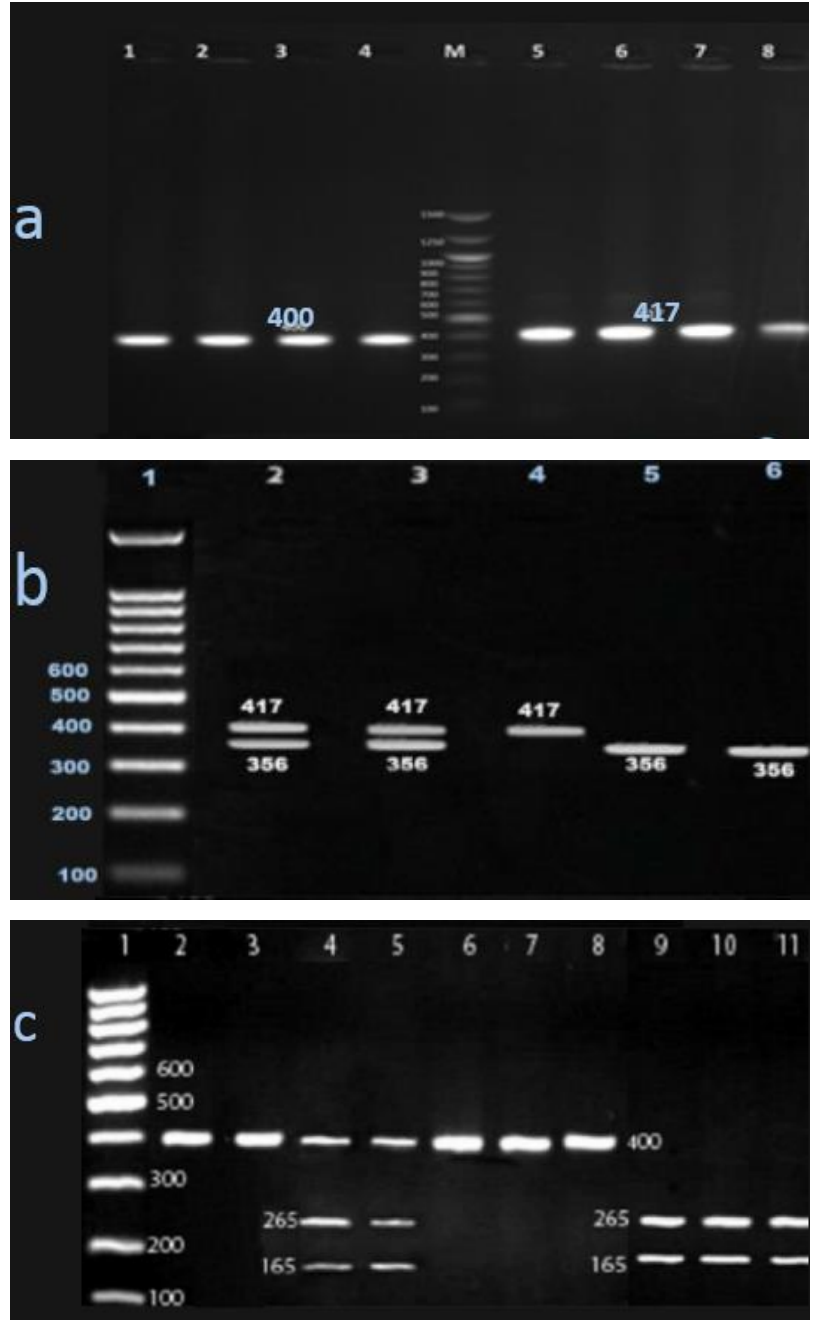

Figure 1a. Electrophoresis of the PCR products of prolactin exons 1 and 5 on agarose gel. Gel was stained with ethidium bromide, Lane 1-4: prolactin (exon5), Lanes 5-8: prolactin (exon1), Lane M: 100-bp DNA ladder. Figure $\mathbf{1 b .}$ Electrophoresis of the digestion products of $X b a \mathrm{I}$ on agarose gel. Gel was stained with ethidium bromide, Lanes 2 and 3: AB genotype, Lane 4: AA genotype, Lanes 5 and 6: BB genotype, Lane 1: 100-bp ladder. Figure 1c. Electrophoresis of the digestion products of $\mathrm{DraI}$ on agarose gel. Gel was stained with ethidium bromide, Lane 2, 6, 7, and 8: AA genotype, Lanes 4 and 5: AB genotype, Lanes 9, 10 and 11: BB genotype, Lane 1: 100-bp DNA Ladder.

Table 1. Relation between the four Egyptian duck breeds (Campbell, Moulard, Pekin and Muscovy) and body weight, egg number per year and egg weight, allelic and genotypic frequencies

\begin{tabular}{|c|c|c|c|c|c|c|c|c|c|c|c|c|c|}
\hline \multirow{3}{*}{ Breed } & \multirow{3}{*}{ BW10 } & \multirow{3}{*}{$\begin{array}{c}\text { Eggs number } \\
\text { /year }\end{array}$} & \multirow{3}{*}{$\begin{array}{c}\text { Egg } \\
\text { weight }\end{array}$} & \multicolumn{4}{|c|}{ Allelic Frequency } & \multicolumn{6}{|c|}{ Genotypic Frequency } \\
\hline & & & & \multicolumn{2}{|c|}{ Exon 1 } & \multicolumn{2}{|c|}{ Exon 5} & \multicolumn{3}{|c|}{ Exon 1 } & \multicolumn{3}{|c|}{ Exon 5} \\
\hline & & & & $\mathbf{A}$ & B & G & C & $\mathbf{A A}$ & $\mathbf{A B}$ & BB & GG & CG & $\mathrm{CC}$ \\
\hline Campbell & $1306.57 \pm 37.32$ & $300-320$ & $65 \mathrm{~g}$ & 00.70 & 00.30 & 0.15 & 0.85 & 0.50 & 0.40 & 0.10 & 0.15 & 0.00 & 0.85 \\
\hline Moulard & $4021.00 \pm 20.49$ & $200-230$ & $60 \mathrm{~g}$ & 00.60 & 00.40 & 00.74 & 00.26 & 0.35 & 0.50 & 0.15 & 0.61 & 0.26 & 0.13 \\
\hline Pekin & $2846.00 \pm 30.02$ & $200-300$ & $60 \mathrm{~g}$ & 00.00 & 1.00 & 0.00 & 1.00 & 0.00 & 0.00 & 1.00 & 0.00 & 0.00 & 1.00 \\
\hline Muscovy & $3740.00 \pm 47.37$ & $100-180$ & $77 \mathrm{~g}$ & 1.00 & 00.00 & 00.85 & 00.15 & 1.00 & 0.00 & 0.00 & 0.75 & 0.20 & 0.05 \\
\hline
\end{tabular}


In similar manner, DraI/RFLP for $P R L$ (exon 5) yielded two homozygous genotypes were GG (400 bp), CC (235 and 165 bp) and heterozygotes are known as genotypes GC (400, 235 and $165 \mathrm{bp}$, Figure 1c). As illustrated in Table 1, all races are polymorphic, except Pekin which was monomorphic (C). Besides, the allele $\mathrm{G}$ was more dominant than allele $\mathrm{C}$ in the four races. Additionally, $P R L$ gene exon 5 of the four manipulated duck breeds, at 10-weeks-body-old weight, had two alleles ( $\mathrm{G}$ and $\mathrm{C}$ ) and three genotypes GG, GC, CC, ducks that had high frequency of allele $\mathrm{C}$ were superior at egg production compared with the other ducks (Table 1).

Genetic polymorphisms of $P R L$ gene covers the coding region of $P R L$ gene (promoter, exon 1 and part of intron 1 and exon 5) between the four Egyptian duck breeds also can be detected by DNA-sequencing methods, Clustal Omega was used to aligned each breed of the four Egyptian duck breeds with each other and with Anas platyrhynchos, PRL gene, cds, AB158611 (A. platyrhynchos, $P R L$ ) presented in the database. The Moulard breed samples revealed that Moulard-1 sequences shared similarity (97.36\%) with Moulard-2. Also, the DNA sequence from Campbell breed samples revealed that the Campbell-1 sequence shared similarity (97.36\%) with Campbell-2. However, Moulard-1 sequences shared high similarity (100\%) with Campbell-2, and Moulard-2 sequences shared high similarity (100\%) with Campbell-1. The alignment between Moulard-1 and Campbell-2 with both Moulard-2 and Campbell-1 showed that Four nucleotide substitutions at nucleotide 132 (A/G), 166 (T/C), $213(\mathrm{C} / \mathrm{T})$ and $378(\mathrm{~T} / \mathrm{C})$, this mutation are considered from the transition type, the other seven nucleotide substitutions at nucleotide $319,325,332$ (T/G), $318,322,326,330(\mathrm{G} / \mathrm{T})$ the SNPs between the sequences are considered from the transversion type.

Furthermore, A. platyrhynchos, PRL shared similarity (99.04\%) with Moulard-1 and Campbell-2 sample, two nucleotide substitutions at nucleotide 267 (G/A) and at nucleotide 412 (A/G), these mutations are considered from the transition type, the other two nucleotide substitutions at nucleotides 312 (T/G) and 314 $(\mathrm{G} / \mathrm{T})$, are considered from the transversion type. Both Moulard-2 and Campbell-1 samples shared similarity (96.40\%) with A. platyrhynchos, PRL, six nucleotide substitutions at nucleotide 132 (A/G), 166 (T/C), 213 (C/T), 267 (G/A), 378 (T/C) and $412(\mathrm{~A} / \mathrm{G})$, the mutations are considered from the transition type, the other nine nucleotide substitutions at nucleotides $312,319,325,332$ (T/G), 314, 318, 322, 326, $330(\mathrm{G} / \mathrm{T})$, are considered from the transversion type (Figure 2) and percent identity matrix of the multiple sequence alignment (Table 2).

The genomic sequences of $P R L$ gene from Pekin and Muscovy breeds revealed that the sequences (Pekin-1 and Pekin-2) also, (Muscovy-1 and Muscovy-2) shared high similarity (100\%) between each other as there is no SNPs between the sequences. However, all Pekin breed samples shared similarity (98.32\%) with A. platyrhynchos, PRL (Table 2). Eight transitions at nucleotides; 267 (G/A) and $412(\mathrm{~A} / \mathrm{G})$. In addition, five transversions at nucleotides; 135 (T/A), 137(C/G), 213(C/T), 312 (T/G) and $314(\mathrm{G} / \mathrm{T})$. All Muscovy ducks shared similarity $(96.40 \%)$ with $A$. platyrhynchos. Six transitions at nucleotides; $132(\mathrm{~A} / \mathrm{G})$, 166 (T/C), 213 (C/T), 267 (G/A), 378 (T/C), 412 (A/G), and nine transversions at $312,319,325,332(\mathrm{~T} / \mathrm{G}), 314$, $318,322,326,330(\mathrm{G} / \mathrm{T})$, were found (Figure 2).

Sequence comparisons among the four studied breeds $P R L$ gene exon1 sequence revealed that Moulard-1 revealed high similarity (100\%) with Campbell-2, (99.28\%) with Pekin and (97.36\%) with Moulard-2, Campbell-1 and Muscovy. As Muscovy resulted high similarity (100\%) with Campbell-1 and Moulard-2, (97.12\%) with Pekin (Table 2).

The four examined duck lines, $P R L$ gene exon 5 sequence, aligned with A. platyrhynchos, $P R L$ disclosed upraised similarity $(100 \%)$ with all Pekin (Pekin-1 and Pekin-2), Moulard-2, Campbell-2 and also Muscovy-1. However, A. platyrhynchos, PRL illustrated similarity (97.25\%) with Moulard-1, Campbell-1 and Muscovy-2 (Table 3). There were five transitions at nucleotides; 5780 (G/A), 5808(T/C), 5822(C/T), 5871(A/G), 5926(G/A), and six transversions at nucleotides; $5766(\mathrm{G} / \mathrm{T}), 5792(\mathrm{~A} / \mathrm{T})$, 5834 (G/T), $6004(\mathrm{~A} / \mathrm{C}), 6007(\mathrm{G} / \mathrm{C})$ and 6029(G/T) (Figure 3). For the sequence comparisons among the four checked duck breeds exon 5 revealed that Moulard-1 exhibited high similarity (100\%) with Campbell-1, Muscovy-2, but $97.25 \%$ with Moulard-2, Campbell-2, Muscovy-1, Pekin-1 and Pekin-2 (Table 3).

The obtained sequences were submitted to Gen bank and have been assigned with accession number; Campbell $P R L$ exon1 allele A (LC565022) and allele B (LC565023), Moulard PRL exon 1 allele A (LC576823) and allele B (LC565024), Pekin PRL exon 1 (LC565026), Muscovy $P R L$ exon 1 (LC565025). Also, the obtained sequences for exon 5 were submitted, Campell $P R L$ exon 5 allele A (LC565015) and allele B (LC565016), Moulard PRL exon 5 allele A (LC565017) and allele B (LC565018), Pekin $P R L$ exon 5 (LC565021), Muscovy PRL exon 5 allele A (LC565019) and allele B (LC565020). 
Table 2. Percent Identity Matrix of DNA multiple sequence alignment for the four Egyptian duck breeds (Campbell, Moulard, Pekin and Muscovy) with each other and other avian species sequences of $P R L$ gene exon 1 published in GenBank database

\begin{tabular}{|c|c|c|c|c|c|c|c|c|c|c|c|c|c|c|}
\hline Species & 1 & 2 & 3 & 4 & 5 & 6 & 7 & 8 & 9 & 10 & 11 & 12 & 13 & 14 \\
\hline 1: M. gallopavo & 100.00 & 77.27 & 78.64 & 76.50 & 76.50 & 76.50 & 76.92 & 76.50 & 76.50 & 76.50 & 85.88 & 84.71 & 97.37 & 94.12 \\
\hline 2: C. moschata & & 100.00 & 91.86 & 98.72 & 98.72 & 98.72 & 97.28 & 97.45 & 97.45 & 97.02 & 90.10 & 86.96 & 87.55 & 86.25 \\
\hline 3: A. anser & & & 100.00 & 94.19 & 94.19 & 94.19 & 93.84 & 95.64 & 95.64 & 95.40 & 90.50 & 87.90 & 85.89 & 82.89 \\
\hline 4: Campbell-1,allele A & & & & 100.00 & 100.00 & 100.00 & 96.40 & 97.36 & 97.36 & 97.12 & 89.30 & 86.75 & 88.44 & 84.73 \\
\hline 5: Moulard-2 allele A & & & & & 100.00 & 100.00 & 96.40 & 97.36 & 97.36 & 97.12 & 89.30 & 86.75 & 88.44 & 84.73 \\
\hline 6: Muscovy-1,2 & & & & & & 100.00 & 96.40 & 97.36 & 97.36 & 97.12 & 89.30 & 86.75 & 88.44 & 84.73 \\
\hline 7: A. platyrhynchos & & & & & & & 100.00 & 99.04 & 99.04 & 98.32 & 88.48 & 85.94 & 87.85 & 84.18 \\
\hline 8: Campbell-2 allele B & & & & & & & & 100.00 & 100.00 & 99.28 & 88.89 & 86.35 & 88.00 & 84.36 \\
\hline 9: Moulard-1 allele B & & & & & & & & & 100.00 & 99.28 & 88.89 & 86.35 & 88.00 & 84.36 \\
\hline 10: Pekin-1,2 & & & & & & & & & & 100.00 & 88.48 & 85.94 & 87.56 & 84.00 \\
\hline 11: $C$. japonica & & & & & & & & & & & 100.00 & 97.11 & 96.41 & 91.67 \\
\hline 12: P. cristatus & & & & & & & & & & & & 100.00 & 95.57 & 92.34 \\
\hline 13: G. gallus B allele & & & & & & & & & & & & & 100.00 & 94.20 \\
\hline 14: P. colchicus & & & & & & & & & & & & & & 100.00 \\
\hline
\end{tabular}

1: Meleagris gallopavo PRL AB605394, 2: Cairina moschata PRL, KM390982, 3: Anser anser PRL, GU984377, 4: Campbell-1 PRL Ex-1, LC565022, 5: Moulard-2 allele A, LC576823, 6: Muscovy PRL Ex1, LC56502, 7: A platyrhynchos PRL, AB158611, 8: Campbell-2 allele B, LC565023, 9: Moulard-1 allele B, LC565024, 10: Pekin, PRL Ex-1, LC565026, 11: Coturnix japonica PRL, AB452962, 12: Pavo cristatus PRL, AB452960, 13: Gallus gallus PRL B allele, JN661569, 14: Phasianus colchicus PRL, AB452961

Table 3. Percent Identity Matrix of DNA multiple sequence alignment for the four Egyptian duck breeds (Campbell, Moulard, Pekin and Muscovy) with each other and other avian species sequences of $P R L$ gene exon 5 published in GenBank database

\begin{tabular}{|c|c|c|c|c|c|c|c|c|c|c|c|c|c|c|}
\hline Species & 1 & 2 & 3 & 4 & 5 & 6 & 7 & 8 & 9 & 10 & 11 & 12 & 13 & 14 \\
\hline 1: Struthio camelus & 100.0 & 87.17 & 87.17 & 87.17 & 87.96 & 87.96 & 87.96 & 87.96 & 87.96 & 88.74 & 81.98 & 81.34 & 81.68 & 83.76 \\
\hline 2: Campbell-1 alleleA_Ex5 & & 100.00 & 100.00 & 100.00 & 97.75 & 97.75 & 97.75 & 97.75 & 97.75 & 97.50 & 83.89 & 84.20 & 84.48 & 83.54 \\
\hline 3: Moulard-1 allele A Ex5 & & & 100.00 & 100.00 & 97.75 & 97.75 & 97.75 & 97.75 & 97.75 & 97.50 & 83.89 & 84.20 & 84.48 & 83.54 \\
\hline 4: Muscovy-2 allele B Ex5 & & & & 100.00 & 97.75 & 97.75 & 97.75 & 97.75 & 97.75 & 97.50 & 83.89 & 84.20 & 84.48 & 83.54 \\
\hline 5: A.platyrhynchos & & & & & 100.00 & 100.00 & 100.00 & 100.00 & 100.00 & 98.75 & 85.68 & 86.65 & 85.75 & 85.09 \\
\hline 6: Campbell-2 allele B Ex5 & & & & & & 100.00 & 100.00 & 100.00 & 100.00 & 98.75 & 85.68 & 86.65 & 85.75 & 85.09 \\
\hline 7: Moulard-2 allele B Ex5 & & & & & & & 100.00 & 100.00 & 100.00 & 98.75 & 85.68 & 86.65 & 85.75 & 85.09 \\
\hline 8: Muscovy-1 allele A Ex5 & & & & & & & & 100.00 & 100.00 & 98.75 & 85.68 & 86.65 & 85.75 & 85.09 \\
\hline 9: Pekin-1,2 & & & & & & & & & 100.00 & 98.75 & 85.68 & 86.65 & 85.75 & 85.09 \\
\hline 10: A. anser & & & & & & & & & & 100.00 & 85.93 & 86.38 & 86.51 & 86.34 \\
\hline 11: G. gallus & & & & & & & & & & & 100.00 & 94.57 & 93.61 & 93.50 \\
\hline 12: P. cristatus & & & & & & & & & & & & 100.00 & 94.57 & 94.43 \\
\hline 13: M. gallopavo & & & & & & & & & & & & & 100.00 & 98.45 \\
\hline 14: Ph. Colchicus & & & & & & & & & & & & & & 100.00 \\
\hline
\end{tabular}

1: Struthio camelus PRL AB36288, 2: Campbell-1 PRL gene Ex5, LC56501, 3: Moulard-1 PRL gene Ex5, LC565017, 4: Muscovy-2 PRL gene Ex5, LC565020, 5: A. platyrhynchos PRL, AB158611,

6: Campbell-2 PRL gene Ex 5, LC565016, 7: Moulard-2 PRL gene Ex5, LC565018, 8: Muscovy-1 PRL gene Ex5, LC565019, 9: Pekin PRL gene Ex5, LC565021, 10: Anser anser PRL, GU984377,

11: Gallus gallus PRL, AB011438, 12: Pavo cristatus PRL, AB605393, 13: Meleagris gallopavo PRL, AH005340, 14: Phasianus colchicus PRL, AB605395 
Anas platyrhynchos, PRLgene Ex 1,AB158611 Pekin-1 duck breed PRL gene Ex 1,alleleB Pekin-2 duck breed PRL gene Ex 1,alleleB Moulard-1 duck breed PRL gene Ex 1,alleleB Campbell-2 duck breed PRL gene Ex 1, alleleB Moulard-2 duck breed PRL gene Ex 1, alleleA Campbell-1 duck breed PRL gene Ex 1, alleleA Muscovy-1 duck breed PRL gene Ex 1, alleleA Muscovy-2 duck breed PRL gene Ex 1,alleleA

Anas platyrhynchos, PRLgene Ex 1, AB158611 Pekin-1 duck breed PRL gene Ex 1,alleleB Pekin-2 duck breed PRL gene Ex 1, alleleB Moulard-1 duck breed PRL gene Ex 1, alleleB Campbell-2 duck breed PRL gene Ex 1, alleleB Moulard-2 duck breed PRL gene Ex 1, alleleA Campbell-1 duck breed PRL gene Ex 1, alleleA Muscovy-1 duck breed PRL gene Ex 1, alleleA Muscovy-2 duck breed PRL gene Ex 1,alleleA

Anas platyrhynchos, PRLgene Ex 1, AB158611 Pekin-1 duck breed PRL gene Ex 1,alleleB Pekin-2 duck breed PRL gene Ex 1 , alleleB Moulard-1 duck breed PRL gene Ex 1 , alleleB Campbell-2 duck breed PRL gene Ex 1,alleleB Moulard-2 duck breed PRL gene Ex 1 , alleleA Campbell-1 duck breed PRL gene Ex 1,alleleA Muscovy-1 duck breed PRL gene Ex 1, alleleA Muscovy-2 duck breed PRL gene Ex 1, alleleA

Anas platyrhynchos, PRLgene Ex 1,AB158611 Pekin-1 duck breed PRL gene Ex 1, alleleB Pekin-2 duck breed PRI gene Fx 1,alleleB Moulard-1 duck breed $P R L$ gene Ex 1, alleleB Campbell-2 duck breed PRL gene Ex 1, alleleB Moulard-2 duck breed PRI gene Ex 1, alleleA Campbell-1 duck breed PRL gene Ex 1 , alleleA Muscovy-1 duck breed PRL gene Ex 1, alleleA Muscovy-2 duck breed PRL gene Ex 1, alleleA

Anas platyrhynchos, PRLgene Ex 1,AB158611 Pekin-1 duck breed PRL gene Ex 1,alleleB Pekin-2 duck breed PRL gene Ex 1,alleleB Moulard-1 duck breed PRL gene Ex 1,alleleB Campbell-2 duck breed PRLgene Ex 1,alleleB Moulard-2 duck breed PRI gene Ex 1, alleleA Moulard-2 duck breed PRL gene Ex 1, alleleA
Campbell-1 duck breed PRL gene Ex 1, alleleA Campbell-1 duck breed PRL gene Ex 1,alleleA
Muscovy-1 duck breed PRL gene Ex 1,alleleA Muscovy-2 duck breedgene Ex 1, alleleA

Anas platyrhynchos, PRLgene Ex 1, AB158611 Pekin-1 duck breed PRL gene Ex 1,alleleB Pekin-2 duck breed PRL gene Ex 1, alleleB Moulard-1 duck breed $P R L$ gene Ex 1 , alleleB Campbell-2 duck breed PRL gene Ex 1,alleleB Moulard-2 duck breed PRL gene Ex 1, alleleA Campbell-1 duck breed PRL gene Ex 1,alleleA Campbell-1 duck breed PRL gene Ex 1, alleleA Muscovy-1 duck breed PRL gene Ex 1, alleleA
Muscovy-2 duck breed PRL gene Ex 1, alleleA

\section{TCTAGA}

Anas platyrhynchos, PRLgene Ex 1,AB158611 Pekin-1 duck breed PRL gene Ex 1, alleleB Pekin-2 duck breed PRL gene Ex 1, alleleB Moulard-1 duck breed PRL gene Ex 1, alleleB Campbell-2 duck breed PRL gene Ex 1, alleleB Moulard-2 duck breed PRL gene Ex 1, alleleA Campbell-1 duck breed PRL gene Ex 1,alleleA Campbell-1 duck breed PRL gene Ex 1, alleleA
Muscovy-1 duck breed PRL gene Ex 1,alleleA Muscovy-1 duck breed PRL gene Ex 1, alleleA
Muscovy-2 duck breed PRL gene Ex 1, alleleA

Anas platyrhynchos, PRLgene Ex 1, AB158611 Pekin-1 duck breed PRL gene Ex 1,alleleB Pekin-2 duck breed PRL gene Ex 1,alleleB Moulard-1 duck breed $P R L$ gene Ex 1, alleleB Campbell-2 duck breed PRL gene Ex 1, alleleB Moulard-2 duck breed PRL gene Ex 1 , alleleA Campbell-1 duck breed PRL gene Ex 1 , alleleA Muscovy-1 duck breed PRL gene Ex 1,alleleA Muscovy-2 duck breed PRL gene Ex 1,alleleA

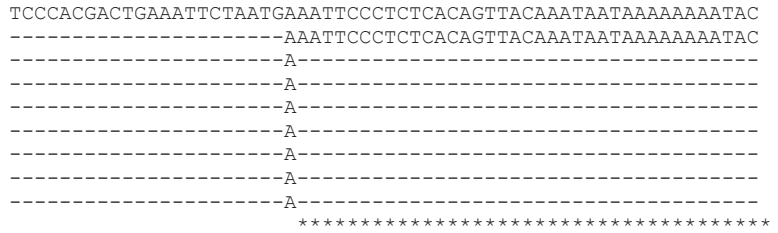

TGAATATGAATGTGGAAGAAAGGCAGTTTGATGTTTGTAATTATCGAGGTAAACTCCACG TGAATATGAATGTGGAAGAAAGGCAGTTTGATGTTTGTAATTATCGAGGTAAACTCCACG
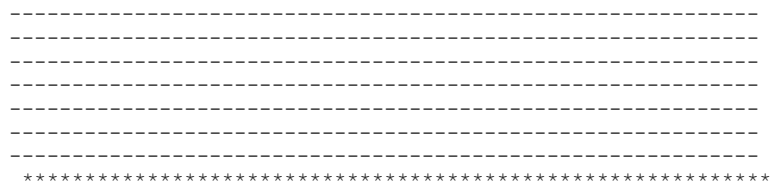

ACCTGTTGAATATATGCAAAATGGACCCCGGATGGTGTATATAAATCTGGTATGTGCAGA

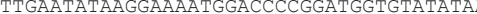

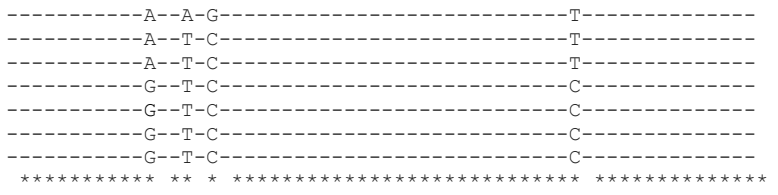

AAATAAAAGCAAGTATTGAGACTTCTTTCTGGCAGAGCAAGTCATCCTACAGGGTCTCTA AAATAAAAGCAAGTATTGAGACTTCTTTCTGGTAGAGCAAGTCATCCTACAGGGTCTCTA

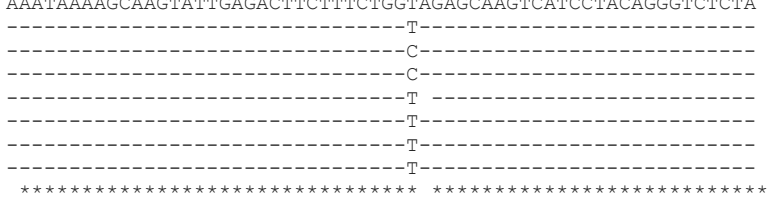

CCATGAGCACCAAGGGGGATTCGTTGGAAGGTAAGACTTTAGCCATTCACTTGTCGATAA CCATGAGCACCAAGGGGGATTCGTTGAAAGGTAAGACTTTAGCCATTCACTTGTCGATAA

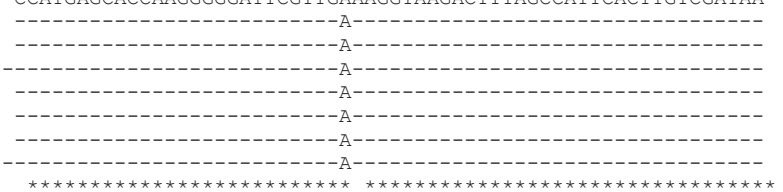

TTTTTATGTTTTTGTTTGTTTGTTTGTTTGTTTTTTACTTTAGATTGAATTTGGAAGTAA TTTTTATGTTTGTTTTTGTTTGTTTGTTTGTTTTTTACTTTAGATTGAATTTGGAAGTAA

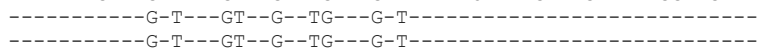

-----------G-T---GT--G--TG---G-T-

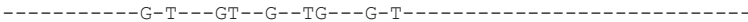

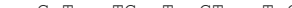

-

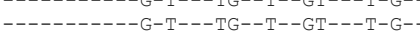

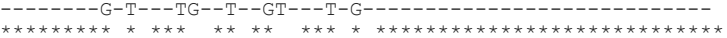

CTGACAGGTAACAACTCTAGAAACTGAGGTCTTCCAAGACATCCAGTTTTCAAGTAATGG CTGACAGGTAACAACTCTAGAAACTGAGGTCTTCCAAGACATCCAGTTTTCGAGTAATGG
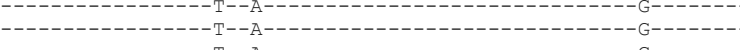

-
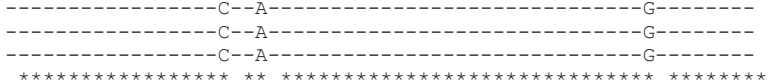
39

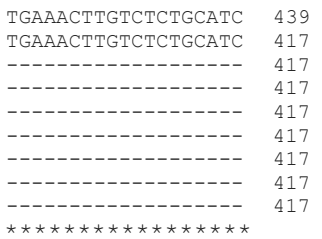

Figure 2. Multiple DNA sequence alignment of PRL Ex1 of the four Egyptian duck breeds (Campbell, Moulard, Pekin and Muscovy) with the Anas platyrhynchos PRL gene Ex 1, AB158611, and nucleotide sequences of alleles A and B showing SNPs at nt 356 and the presence of $\mathrm{XbaI}$ restriction site ( $\underline{\mathrm{T} \downarrow \mathrm{CTAGA}})$ in alleles B. 
Anas platyrhynchos PRLgene, cds, AB158611 Pekin-1 duck breed PRL gene Ex 5, allele $C$ Pekin-2 duck breed PRL gene Ex 5, allele C Muscovy-1 duck breed $P R L$ gene Ex 5, allele Moulard-2 duck breed PRL gene Ex 5, allele C Campbell-2 duck breed PRL gene Ex 5,allele C Campbell-1 duck breed PRL gene Ex 5, allele Moulard-1 duck breed $P R L$ gene Ex 5, allele G Muscovy-2 duck breed PRL gene Ex 5, allele G

Anas platyrhynchosPRLgene, cds, AB158611 Pekin-1 duck breed PRL gene Ex 5,allele C Pekin-2 duck breed $P R L$ gene Ex 5, allele C Muscovy-1 duck breed PRL gene Ex 5, allele C Moulard-2 duck breed PRL gene Ex 5, allele C Campbell-2 duck breed PRL gene Ex 5,allele C Campbell-1 duck breed PRL gene Ex 5,allele Moulard-1 duck breed PRL gene Ex 5, allele G Muscovy-2 duck breed PRL gene Ex 5, allele G

\section{AAATTT}

Anas platyrhynchos PRLgene, cds, AB158611 Pekin-1 duck breed PRL gene Ex 5, allele C Pekin-2 duck breed PRL gene Ex 5, allele C Muscovy-1 duck breed PRL gene Ex 5, allele C Moulard-2 duck breed PRL gene Ex 5, allele C Campbell-2 duck breed PRL gene Ex 5,allele C Campbell-1 duck breed PRL gene Ex 5,allele Moulard-1 duck breed PRL gene Ex 5, allele G Muscovy-2 duck breed $P R L$ gene Ex 5, allele G

Anas platyrhynchosPRLgene, cds, AB158611 Pekin-1 duck breed PRL gene Ex 5, allele C Pekin-2 duck breed $P R L$ gene Ex 5, allele Muscovy-1 duck breed PRL gene Ex 5, allele C Moulard-2 duck breed $P R L$ gene Ex 5, allele C Campbell-2 duck breed $P R L$ gene Ex 5,allele C Campbell-1 duck breed $P R L$ gene Ex 5,allele Moulard-1 duck breed PRL gene Ex 5,allele G Muscovy-2 duck breed PRL gene Ex 5, allele G

Anas platyrhynchosPRLgene, cds, AB158611 Pekin-1 duck breed PRL gene Ex 5,allele C Pekin-2 duck breed PRL gene Ex 5, allele C Muscovy-1 duck breed $P R L$ gene Ex 5, allele C Moulard-2 duck breed PRL gene Ex 5, allele C Campbell-2 duck breed $P R L$ gene Ex 5,allele C Campbell-1 duck breed PRL gene Ex 5,allele G Moulard-1 duck breed PRL gene Ex 5,allele G Muscovy-2 duck breed PRL gene Ex 5, allele G

Anas platyrhynchosPRLgene, cds, AB158611 Pekin-1 duck breed PRL gene Ex 5, allele C Pekin-2 duck breed PRL gene Ex 5, allele Muscovy-1 duck breed PRL gene Ex 5, allele C Moulard-2 duck breed $P R L$ gene Ex 5, allele C Campbell-2 duck breed PRL gene Ex 5,allele C Campbell-1 duck breed PRL gene Ex 5,allele G Moulard-1 duck breed PRL gene Ex 5,allele G Muscovy-2 duck breed $P R L$ gene Ex 5,allele G

Anas platyrhynchos PRLgene, cds, AB158611 Pekin-1 duck breed PRL gene Ex 5, allele C Pekin-2 duck breed $P R L$ gene Ex 5, allele Muscovy-1 duck breed PRL gene Ex 5, allele C Moulard-2 duck breed PRL gene Ex 5,allele C Campbell-2 duck breed PRL gene Ex 5,allele C Campbell-1 duck breed PRL gene Ex 5, allele G Moulard-1 duck breed $P R L$ gene Ex 5,allele G Muscovy-2 duck breed PRL gene Ex 5, allele G

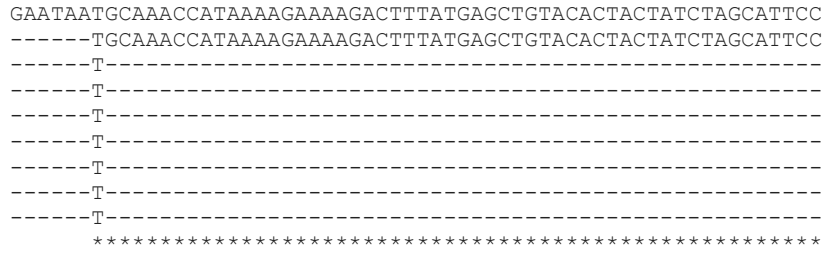

TCAAGGCCAGTATTTCTTAGTTCTCTGTCCTACATCCAGTCAGATTCATTATTATCTACT TCAAGGCCAGTATTTCTTAGTTCTCTGTCCTACATCCAGTCAGATTCATTATTATCTACT

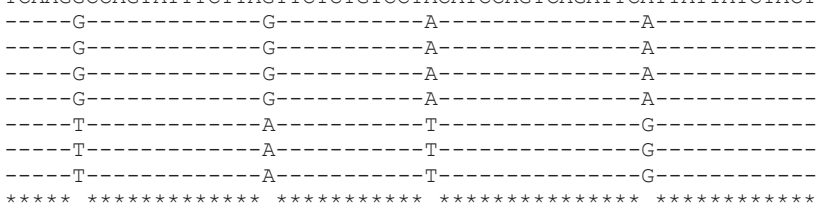

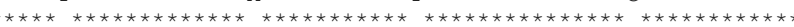

ACGGTATCATTTTGTGCCTTTAGGTTCATTCTGGCGACATTGGAAATGAAATTTATTCTC ACGGTATCATTTTGTGCCTTTAGGTTCATTCTGGCGACATTGGAAATGAAATTTATTCTC

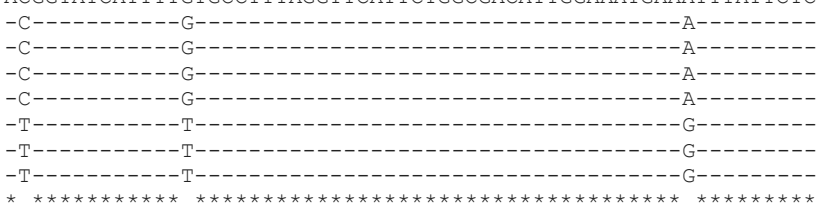

AGTGGGAAGGCCTTCCATCCTTGCAACTTGCCGATGAGGACTCCAGACTCTTTGCCTTTT AGTGGGAAGGCCTTCCATCCTTGCAACTTGCCGATGAGGACTCCAGACTCTTTGCCTTTT

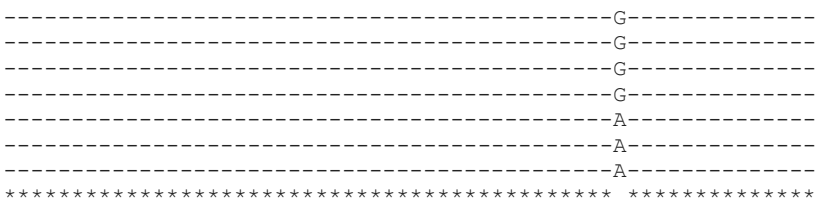

ACAACCTGCTGCATTGCCTCCGCAGAGATTCCCACAAAATTGACAACTATCTCAAGGTTT ACAACCTGCTGCATTGCCTCCGCAGAGATTCCCACAAAATTGACAACTATCTCAAGGTTT
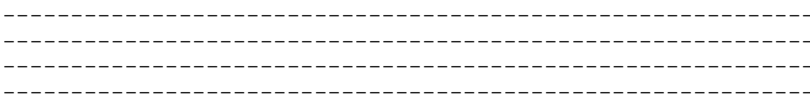

-

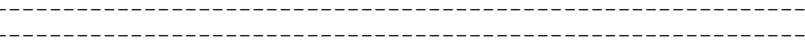

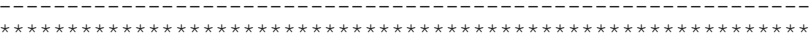

TGAAGTGCCGCCTAATACATGATAGCAATTGCTAAGTACTCCTGGGCTTCATCGCTTACT TGAAGTGCCGCCTAATACATGATAGCAATTGCTAAGTACTCCTGGGCTTCATCGCTTACT

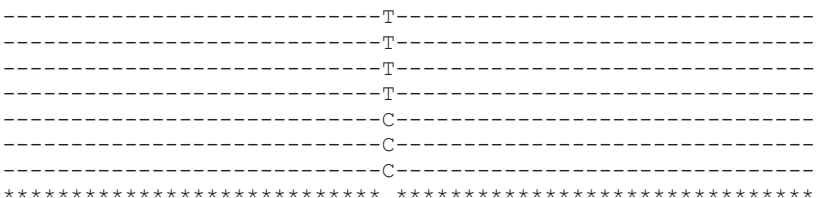

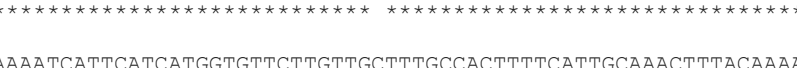
AAAATCATTCATCATGGTGTTCTTGTTGCTTTGCCACTTTTCATTGCAAACTTTACAAAA

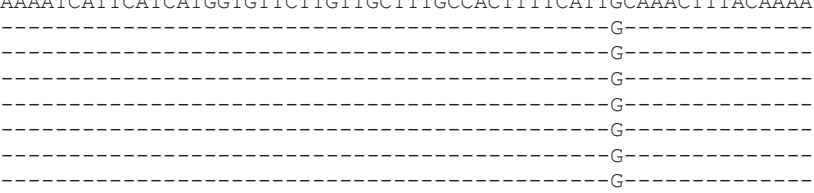

5880

174

174

174

174

174

174
174

5940
6120

400

400

400

400

400

400

400

Figure 3. Multiple DNA sequence alignment of $P R L$ Ex 5 of the four Egyptian duck breeds (Campbell, Moulard, Pekin and Muscovy) with the Anas platyrhynchos PRL gene Ex 5, AB158611, and nucleotide sequences of alleles $\mathrm{G}$ and $\mathrm{C}$ showing SNPs position at nt 165 and the presence of DraI restriction site (3'AAA $\downarrow$ TTT 5') (underlined) in alleles C. 


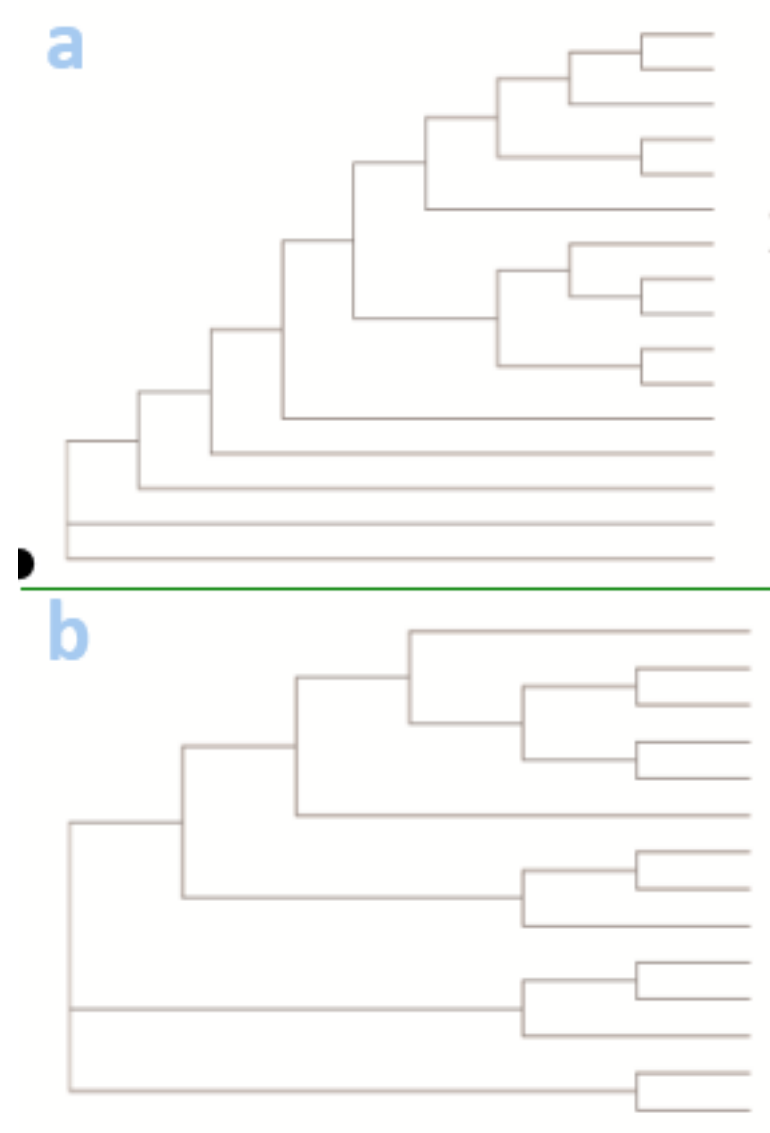

\author{
Meleagris_gallopavo_PRL_AB605394 0.06315 \\ Phasianus_colchicus_PRL_promoter_region\&.partial_cds_AB452961 -0.00433 \\ Gallus_gallus_prolactin_PRL_B_allele_promoter_region_exon_1_JN661569_- 0.01509 \\ Cotumix_japonica_PRL_promoter_region\&partial_cds_AB452962 0.0023 \\ Pavo_cristatus_PRL_promoter_region\&partial_cds_AB452960 0.02662 \\ Anser_anser_prolactin_PRL_gene_complete_cds_GU984377 0.02659 \\ Anas_platymynchos_PRL_gene_cds_AB158611 0.00906 \\ Campbell-2_duck_breed_PRL_allele_B_Ex_1 0 \\ Moulard-1_duck_breed_PRL_allele_B_Ex_1_Ex_1 0 \\ Pekin-1_duck_breed_PRL_allele_B_Ex_10 \\ Pekin-2_duck_breed_PRL_allele_B_Ex_1 0 \\ Cairina_moschata_domestica_PRL_promoter_region 0.00841 \\ Campbell-1_duck_breed_PRL_allele_A_Ex_1 0 \\ Muscovy-1_duck_breed_PRL_allele_A_Ex_10 \\ Moulard-2_duck_breed_PRL_allele_A_Ex_10 \\ Muscovy-2_duck_breed_PRL_allele_A_Ex_10 \\ Struthio_camelus_prolactin_PRL_gene_complete_cds_AB362880 0.07643 \\ Gallus_gallus_prolactin_PRL_complete 0.03014 \\ Pavo_cristatus_prolactin_PRL_gene_complete_cds_AB605393 0.02421 \\ Meleagris_gallopavo_prolactin_PRL_gene_complete_cds_AH005340 0.00589 \\ Phasianus_colchicus_prolactin_PRL_gene_complete_cds_AB605395 0.00959 \\ Anser_anser_prolactin_PRL_gene_complete_cds_GU984377 0.00302 \\ Campbell_breed_PRL__alleleA_Ex5_LC565015 0 \\ Moulard_breed_PRL_alleleA_Ex5_LC565017_0 \\ Muscovy_breed_PRL_alleleB_Ex5_LC565020_0 \\ Anas_platyrhynchos_PRL_Ex5_AB158611 0 \\ Campbell_breed_PRL_alleleB_Ex5_LC565016_0 \\ Pekin_breed_PRL_Ex5_LC565021_0 \\ Moulard_breed_PRL_alleleB_Ex5_LC565018_0 \\ Muscovy_breed_PRL_alleleA_Ex5_LC565019_0
}

Figure 4a. Phylogenetic tree of the Multiple DNA sequence alignment of the four Egyptian duck breeds (Moulard, Pekin, Campbell and Muscovy) $P R L$ gene exon 1 with the other sequences of avian prolactin gene species published in GenBank database. Figure 4b. Phylogenetic tree of the Multiple DNA sequence alignment of the Egyptian duck breed $P R L$ gene exon 5 with the other sequences of avian prolactin gene species published in GenBank database.

Sequence comparison of $P R L$ gene exon 1, between the four Egyptian duck breeds and other avian Species, appeared in percent identity matrix of DNA multiple sequence alignment of exon 1 (Table 2) and phylogenetic tree (Figure 4a). Likewise, DNA sequence comparison of exon 5 , between the four breeds, and other birds, were illustrated in percent identity matrix of DNA multiple sequence alignment of exon 1 (Table 3) and phylogenetic tree (Figure $4 b$ ).

Regards to the phylogenetic tree, of Egyptian duck breeds, $P R L$ gene exon1, the locus of Moulard-1 was related to Campbell-2 and Pekin, more than Moulard-2, Campbell-1 and Muscovy. However, the locus of Muscovy was related to Moulard-2, Campbell-1, more than Pekin (Figure 4a). For exon 5 tree, the locus of Moulard-1 was related to Campbell-2, Muscovy-2, more than Moulard-2, Campbell-2, Muscovy-1and Pekin (Figure 4b).

Lastly, prolactin gene sequence, in the four studied strains, was aligned with Duck genome, by using the BLAST program. The results of these alignments represent Duck prolactin ( $P R L)$ gene sequence on chromosome 2 (APL 2), Anas platyrhynchos isolate PK2015 chromosome 2, IASCAAS Peking Duck PBH1.5 ranging from 49241262 to 49241678 for prolactin promoter exon 1 gene, and ranging from 49246949 to 49247348 for exon 5.

\section{DISCUSSION}

Research on the PRL gene have been widely carried out, the avian PRL gene is highly conserved and most 
sequence polymorphisms in the PRL gene occur in $5^{\prime}$ flanking region, $3^{\prime}$ flanking region (Kansaku et al., 2008). The literatures focused on polymorphisms of PRL gene in $5^{\prime}$ flanking region (promoter region) which has been considered as an excellent experimental model for studying both tissue-specific and hormonally regulated activation of gene transcription The literature lightened up PRL gene polymorphism, in $5^{\prime}$ flanking region (promoter region) which has been respected as a perfect experiential example, for exploring both tissue-special and hormonally managed activation of gene transcription (Elsholtz et al., 1991; Li et al., 2009; Wang et al., 2011; Chang et al., 2012).

In this study, the results showed that Genetic polymorphisms of $P R L$ gene by RFLP analysis, so the restriction enzymes XbaI and DraI have been used. The results of RFLP characterization analysis using the XbaI enzyme showed that the four Egyptian duck breeds PRL gene exon 1 and part of intron 1 at 10-weeks-old body weight had two alleles (A and B) and three genotypes AA, $\mathrm{AB}, \mathrm{BB}$, ducks with high frequency of allele A superior at egg weight compared to others. Into the bargain, the association of intron 1 polymorphism of $P R L$ gene with egg weight was studied (Li et al., 2009) and agreed with present study. PCR-RFLP produced three genotypes AA, $\mathrm{BB}$, and $\mathrm{AB}$, and ducks of $\mathrm{BB}$ genotype were higher egg production and superior egg weight at 30 weeks than $A B$ genotypes, which in agreement with this study. Wang et al. (2011) found variations in exons 2, 4 and 5 in local Chinese ducks, but the relationship with annual egg production was shown by exon 5 . The prolactin gene SNP at intron $1, \mathrm{C} \rightarrow \mathrm{A}$ mutation at position 386 at introns which can be detected by $X b a \mathrm{I}$ enzyme (Mazurowski et al., 2016), identifying two alleles $G$ and $T$, and three genotypes GG, TG and TT. PRL/XbaI locus was found polymorphic in Pekin and Moulard duck populations, while monomorphic in Muscovy duck breed. Thus, the result would be useful as a control for genetic equilibrium in Muscovy ducks. In addition, Bai et al. (2019) studied the association between $P R L$ gene with egg production. They found three genotypes AA, AG, GG and ducks that have GG genotype were greater in egg weight and egg production when compared to the other genotypes. Prolactin hormone gene can use as a genetic marker for reproductive traits (Bai et al., 2019; Basumatary et al., 2019). The C359A polymorphism was reported in Khaki Campbell duck as being associated with egg production at 300 days, with ducks with the GT genotype producing a greater number of eggs than those with TT and GG genotypes (Chuekwon and Boonlum, 2017).

RFLP characterization analysis results by using the DraI enzyme on the exon $5 P R L$ gene fragment resulted that four Egyptian duck breed $P R L$ gene exon 5 at 10weeks-body-old weight had two alleles ( $\mathrm{G}$ and $\mathrm{C}$ ) and three genotypes GG, GC, CC, ducks that had high frequency of allele $\mathrm{C}$ were superior at egg production compared with others. Also, the results of PRL/DraI in Bayang ducks resulted three genotypes consisting of homozygotes (CC), heterozygotes (CT) and homozygotes (TT) with frequencies of $0.684,0.293$ and 0.21 , respectively. The proportion of alleles obtained in the Prolactin (PRL|XbaI) gene fragments in the Bayang duck studied has a frequency of genotype and allele not much different from the genotype and allele frequency values in the study of Shaoxing local Chinese ducks (Yurnalis et al., 2019). These are in accordance with present results. The different distribution of genotypes in different duck populations may be described to the different genetic background of these populations (Wang et al., 2011). Since the chicken PRL gene had been cloned and sequenced (Watahikiet al., 1989), most research focused on polymorphism detection in this gene.

For genetic polymorphism of PRL gene, comprising the promoter, exon 1, part of intron 1 and exon 5, the genomic sequence comparisons between four Egyptian duck breeds $P R L$ gene exon 1 sequence revealed that Moulard-1 breed sample shared high similarity (100\%) with Campbell-2, (99.28\%) with Pekin and (97.36\%) with Moulard-2, Campbell-1 and Muscovy breed samples. As Muscovy resulted high similarity (100\%) with Campbell-1 and Moulard-2, and (97.12\%) with Pekin. For the PRL gene exon 5 the sequence comparisons revealed that Moulard-1 shared high similarity (100\%) with Campbell1, Muscovy-2, but shared similarity (97.25\%) with Moulard-2, Campbell-2, Muscovy-1 and two samples of Pekin-1 and Pekin-2. Several SNPs were revealed from the both type (transition and transversion) for the two exons 1 and 5. However, the difference in genotypes between four Egyptian duck breed resulted from the presence of SNPs at $\mathrm{T} / \mathrm{C}$ mutation position $378 \mathrm{bp}$ in intron 1 region and $\mathrm{A} / \mathrm{G}$ mutation at position $5871 \mathrm{bp}$ in exon 5 region (Accession no. AB158611).

A great number of SNPs were reported in $P R L$ gene for chicken. From direct sequencing and association analysis, Cui et al. (2006) got six SNPs (C-2402T, C2161G, T-2101G, C-2062G, T-2054A and G-2040A) and a 24-bp indel (insertion-deletion) showed that the 24-bp indel was correlated to egg production and chicken 
broodiness. Also, three mutations screened by Liu et al. (2007) (C-1607T, C-5749T and T-5821C) showed a link between different haplotypes and production of eggs. In geese, three SNPs (A-401G, G-268A and T-266A) were screened in the 5'-proximal region of $P R L$ gene and statistical analysis indicated that these polymorphisms have the potential to be used for egg production in molecular breeding (Jiang et al., 2009). All the above studies showed that $P R L$ is an effective candidate gene for production eggs.

Assorted gene SNPs, concerning egg-laying traits in both chicken and geese, have been exposed, with few reviews in ducks (Kang et al., 2012; Kulibaba, 2015; Alsiddig et al., 2017; Mohamed et al., 2017; Feng et al., 2018). There was a number of new SNPs, not the 12 SNPs hit in the six native Chinese duck strains (Wang et al., 2011). These results showed that the duck $P R L$ gene in these duck populations is rich in polymorphisms in these duck populations.

Sequence comparisons between genomic sequence of $P R L$ gene exon 1 from the four Egyptian duck lines and from the other avian species showed that sequence alignments of Moulard allele B and Campbell allele B shared similarity $(99.04 \%, 97.45 \%, 95.64 \%, 88.00 \%$, $76.50 \%, 88.89 \%, 86.35 \%$ and $84.36 \%$ ), Muscovy exon 1 , Moulard allele A and Campbell allele A shared similarity (96.40\%, 98.72\%, 94.19\%, 88.44\%, 76.50\%, 89.30\%, $86.75 \%$ and $84.73 \%)$ and also, Pekin exon 1 shared similarity $(98.08 \%, 97.02 \%, 95.16 \%, 87.56 \%, 76.00 \%$, $88.48 \%, 85.94 \%$ and $84.00 \%$ ) with $P R L$ gene of $A$. platyrhynchos (Moulard duck), Muscovy duck, geese, chicken, turkey, Japanese quail, Indian peafowl, and ringnecked pheasant, respectively. Also, the sequence comparisons results of Egyptian duck breeds PRL gene exon 5 and the other avian species revealed that Moulard allele A, Campbell allele A, and Muscovy allele B) shared similarity $(97.75 \%, 97.50 \%, 83.89 \%, 84.48 \%, 83.54 \%$, 87.17\% and 84.20\%) and (Moulard allele B , Campbell allele B, Muscovy allele A and Pekin) shared similarity $(100.00 \%, 98.75 \%, 85.68 \%, 85.75 \%, 85.09 \%, 87.96 \%$ and 86.65) with A. platyrhynchos (Moulard duck), goose, chicken, turkey, ring-necked pheasant, Ostrich and Indian peafowl, respectively.

The PRL gene has been cloned formerly in divergent avian species like pigeon, duck, chicken, quail, turkey and pigeon (Liu et al. 2008). Duck $P R L$ was found to have sequence identity $(92.0 \%, 91.7 \%$ and $91.4 \%)$ at the cDNA level compared to $P R L$ of chicken, turkey and quail, respectively. The mature duck $P R L$ has an overall similarity with a comparable region of chicken (95.5\%), turkey (92.5\%) and quail (95.5\%) PRL (Kansaku et al., 2005). Also, the sequence analysis of the proximal region, of duck PRL promoter, displayed a high plane of similarity to turkey and chicken PRL promoter. These results viewed that the mechanisms, modulating the gene expression, may be vastly conserved in avian species (Kansaku et al., 2005). Over and above, since the avian PRL gene was cloned and sequenced, most researches illuminate new polymorphic sites in this gene (Rashidi et al., 2012).

The phylogenetic tree of exons 1 and 5 for DNA $P R L$ gene in the different avian species showed that the locus of four Egyptian duck was related to $P R L$ gene of $A$. platyrhynchos, A. anser more than of G. gallus, M. gallopavo, P. colchicus, $S$. camelus and P. cristatus. This clustering based on both of nucleotide of $P R L$ gene clearly showed that the phylogenetic inter-relationship among these species and is generally in agreement with the known species relationships. This tree was constructed using Mr. Bayes, employing a previously calculated gene family with multiple sequence alignment (Huelsenbeck and Ronquist, 2001; Siltberg and Liberles, 2002).

\section{CONCLUSION}

The results of this study manipulating the four Egyptian duck breeds; Campbell, Moulard, Muscovy and Pekin, supported previous findings. That there are many SNPs found in the sequences in the four Egyptian duck breeds. The utmost vital ones, are those found at the restriction sites of $X b a \mathrm{I}$, for the amplified fragment contained the promotor, exon 1 and intron 1 (T378C), and exon 5/DraI (A5871G). These data could serve as a basis for further insight into this avian gene. Owing to the fact that the genotypes distribution in this studied between the four Egyptian duck breeds was not in Hardy-Weinberg equilibrium, to confirm the observed associations, further research should be applied to a broad and more homogeneous population of ducks. In addition, a survival evaluation and post slaughter examination of ducks must be carried out to ascertain any potential connections with polymorphic variants in the PRL gene present in duck.

\section{DECLARATIONS}

\section{Acknowledgements}

The authors sincere gratefulness to the Nubaria experimental farm, for kind assistance in collecting the blood samples of the duck breeds understudy, needed for accomplishment of this research. 


\section{Authors' contributions}

All authors contributed evenly throughout the manuscript. All authors participated equally in the study plan and design. EME, NMS, DMM and MAM collected the samples from different locations and isolated the nucleic acids. NMS, DMM and MAM carried out PCR and sequencing analyses. NMS, DMM, MAM and KFM carried out the statistical analysis of data and reported the results of the molecular analysis. KFM, NMS and MAM collaborated on writing, revising, and improvement of the article for publication. All authors read and approved the final.

\section{Competing interests}

The authors declare that they don't have any conflict of interest.

\section{REFERENCES}

Alsiddig MA, Yu SG, Pan ZX, Widaa H, Badri TM, Chen J, and Liu HL (2017). Association of single nucleotide polymorphism in melatonin receptor 1A gene with egg production traits Journal in Yangzhou geese. Animal Genetics, 48: 245-249. DOI: https://www.doi.org/ 10.1111/age.12517

Asiamah AC, Zou, K, Lu LL, Zhang SW, Xue Y, Su Y, and Zhao Z (2019). Genetic effects of polymorphisms of candidate genes associated with ovary development and egg production traits in ducks. Animal Reproduction Science, 11: 106-219. DOI: https://www.doi.org/10.1016/j.anireprosci. 2019.106219

Baeza E (2006). Effects of genotype, age and nutrition on intramuscular lipids and meat quality. In Symposium COA/INRA Scientific Cooperation in Agriculture. November, pp. 7-10. Available at: http://www.angrin.tlri.gov.tw/INRA/o5.pdf

Bai DP, Hu YQ, Li YB, Huang ZB, and Li A (2019). Polymorphisms of the prolactin gene and their association with egg production traits in two Chinese domestic ducks. British poultry science, 60(2): 125129. DOI: https://www.doi.org/10.1080/00071668.2019.1567909

Basumatary K, Das B, Borah P, Barkalita L, Bharali K, and Tamuly S (2019). Polymorphism of prolactin receptor gene in indigenous ducks of Assam. Journal of Entomology and Zoology Studies, 7(1): 922-925. Available

at: http://www.entomoljournal.com/archives/2019/vol7issue1/PartO/71-143-769

Chang MT, Cheng YS, and Huang MC (2012). Association of prolactin haplotypes with reproductive traits in Tsaiya ducks. Animal reproduction science, 135(1-4):91-96. DOI: https://www.doi.org/10.1016/j.anireprosci.2012.08.024

Chuekwon K, and Boonlum S (2017). Association of Prolactin Gene with Egg Production in Khaki Campbell Ducks. Walailak Journal of Science and Technology, 14(11): 849-853. Available at: http://wjst.wu.ac.th/index.php/wjst/article/download/1934/723/2902 9

Cui JX, Du HL, Liang Y, Deng XM, Li N, and Zhang XQ (2006). Association of polymorphisms in the promoter region of chicken prolactin with egg production. Poultry Science, 85(1):26-31. DOI: https://www.doi.org/10.1093/ps/85.1.26

Elsholtz HP, Lew AM, Albert PR, and Sundmark VC (1991). Inhibitory control of prolactin and Pit-1 gene promoters by dopamine. Dual signaling pathways required for D2 receptor-regulated expression of the prolactin gene. Journal of Biological Chemistry, 266(34): 22919-22925. Available at: https://www.jbc.org/content/266/34/22919.short

Feng P, Zhao W, Xie Q, Zeng T, Lu L, and Yang L (2018). Polymorphisms of melatonin receptor genes and their associations with egg production traits in Shaoxing duck. Asian-Australasian Journal of Animal Science, 31(10): 1535-1541. DOI: https://www.doi.org/10.5713/ajas.17.0828

Huelsenbeck JP, and Ronquist F (2001). Mr. Bayes: Bayesian inference of phylogeny. Bioinformatics, 17: 754-755. DOI:https://doi.org/10.1093/bioinformatics/17.8.754

Jiang RS, Zhang LL, Geng ZY, Yang T, and Zhang SS (2009). Single nucleotide polymorphisms in the 5'-flanking region of the prolactin gene and the association with reproduction traits in geese. South African Journal of Animal Science, 39: 83-87. DOI: https://www.doi.org/10.4314/sajas.v39i1.43550

Kang L, Zhang N, Zhang Y, Yan H, Tang H, Yang C, Wang H, and Jiang $Y$ (2012). Molecular characterization and identification of a novel polymorphism of $200 \mathrm{bp}$ indel associated with age at first egg of the promoter region in chicken follicle-stimulating hormone receptor (FSHR) gene. Molecular Biology Reports, 39: 2967-2973. DOI: https://www.doi.org/10.1007/s11033-011-1058-x

Kansaku N, Hiyama G, Sasanami T, and Zadworny D (2008). Prolactin and growth hormone in birds: Protein structure, gene structure and genetic variation. The Journal of Poultry Science, 45(1): 1-6. DOI: https://www.doi.org/10.2141/jpsa.45.1

Kansaku N, Ohkubo T, Okabayashi H, Guémené D, Kuhnlein U, Zadworny D, and Shimada K (2005). Cloning of duck PRL cDNA and genomic DNA. General and Comparative Endocrinology, 141(1): 39-47. DOI: https://www.doi.org/10.1016/j.ygcen.2004.11.017

Kulibaba RA (2015). Polymorphism of Growth Hormone, Growth Hormone Receptor, Prolactin and Prolactin Receptor genes in connection with egg production in Poltava clay chicken. Sel'Skokhozyaistvennaya Biologia, 50(2): 198-207. DOI: https://www.doi.org/10.15389/agrobiology.2015.2.198eng

Larkin MA, Blackshields G, Brown NP, Chenna R, McGettigan PA, McWilliam H, Valentin F, Wallace IM, Wilm A, and Lopez R (2007). Clustal W and Clustal X version 2.0. Bioinformatics, 23(21): 2947-2948. DOI: https://www.doi.org/10.1093/bioinformatics/btm404

Li HF, Zhu WQ, Chen KW, Zhang TJ, and Song WT (2009). Association of polymorphisms in the intron 1 of duck prolactin with egg performance. Turkish Journal of Veterinary and Animal Sciences, 33 (3): 193-197. DOI: https://www.doi.org/10.3906/vet-0709-4

Li J, Liang A, Li Z, Du C, Hua G, Salzano A, Campanile G, Gasparrini $\mathrm{B}$, and Yang L (2017). An association analysis between PRL genotype and milk production traits in Italian Mediterranean river buffalo. Journal of Dairy Research, 84: 430-433. DOI: https://www.doi.org/10.1017/s0022029917000693

Liu HG, Wang XH, Liu YF, Zhao XB, Li N, and Wu CX (2007). Analysis of the relationship between codon frequency of prolactin gene and laying performance in five chicken breeds. Progress in Biochemistry and Biophysics, 34: 1101-1106. Available at: http://www.pibb.ac.cn/

Liu Z, Shiz D, Liu Y, Lim Y, Huangy M, and Yao BH (2008). Molecular cloning and characterization of the Magang goose prolactin gene. General and Comparative Endocrinology, 155: 208-216. DOI: https://www.doi.org/10.1016/j.ygcen.2007.04.017

Mazurowski A, Frieske A, Wilkanowska A, Kokoszyński D, Mroczkowski S, Bernacki Z, and Maiorano G (2016). Polymorphism of prolactin gene and its association with growth and some biometrical traits in ducks. Italian Journal of Animal Science, 15: 200-206. DOI: https://www.doi.org/10.1080/1828051X.2016.1153405

Mohamed MMO, Shaaban AH, Hassanin AAI, and Hussein WA (2017). Polymorphism of prolactin gene and its association with egg 
Sabry et al., 2020

production trait in four commercial chicken lines. Journal of the Hellenic Veterinary Medical Society, 68: 391-404. DOI: https://www.doi.org/10.12681/jhvms.15502

Narhari D (2009). Housing and management of ducks. IV World Waterfowl Conference, 11-13 November, 2009, Thrissur, India, pp. 45-47. Available http://www.waterfowl2009.vetcos.com/proceedings

Rashidi H, Rahimi-Mianji G, Farhadi A, and Gholizadeh M (2012). Association of prolactin and prolactin receptor gene polymorphisms with economic traits in breeder hens of indigenous chickens of Mazandaran province. Iranian journal of Biotechnology, 10(2): 129-135. Available at: http://www.ijbiotech.com/

Sadar MJ, Guzman DSM, Burton AG, Byrne BA, Wiggans KT, and Hollingsworth SR (2014). Mycotic keratitis in a khaki campbell duck (Anas platyrhynchos domesticus). Journal of avian medicine $\begin{array}{lll}\text { and } & \text { surgery, 28(4): } & \text { 322-329. }\end{array}$ https://www.doi.org/10.1647/2013-050

Sarvestani BAS, Niazi A, Zamiri MJ, and Taromsari DM (2013). Polymorphisms of prolactin gene in a native chicken population and its association with egg production. Iranian Journal of Veterinary

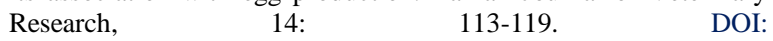
https://www.doi.org/10.22099/IJVR.2013.1584

Shamsalddini S, Mohammadabadi MR, and Esmailizadeh AK (2016). Polymorphism of the prolactin gene and its effect on fiber traits in goat. Genetika, 52(4): 461-465. DOI: https://www.doi.org/10.7868/S0016675816040093

Shokrzadeh M, and Mohammadpour A (2018). Evaluation of a modified salt-out method for DNA extraction from whole blood lymphocytes: A simple and economical method for gene polymorphism. Pharmaceutical and Biomedical Research, 4(2). DOI: https://www.doi.org/10.18502/pbr.v4i2.218

Siltberg J, and Liberles DA (2002). A simple covarion-based approach to analyze nucleotide substitution rates. Journal of Evolutionary Biology, 15(4): 588-594. DOI: https://www.doi.org/10.1046/j.14209101.2002.00416.x

Tempfli K, Konrád S, KovácsnéGaál K, Pongrácz L, and Papp BÁ (2015). Prolactin, dopamine receptor D1 and Spot $14 \alpha$ polymorphisms affect production traits of Hungarian Yellow hens. Livestock Science, p. 174. DOI: https://www.doi.org/10.1016/j. $\underline{\text { livsci.2015.01.012 }}$
Veeramani P, Prabakaran R, Sivaselvam SN, Sivakumar T, Selvan ST, and Karthickeyan SMK (2016). Phylogenetic analysis of six duck populations. Indian Journal of Animal Research, 50(4): 626-628. DOI: https://www.doi.org/10. 18805/ijar.9301

Wang C, Liang Z, Yu W, Feng Y, Peng X, Gong Y, and Li S (2011). Polymorphism of the prolactin gene and its association with egg production traits in native Chinese ducks. South African Journal of Animal Science,41:63-69. Available at: http://www.sasas.co.za

Watahiki M, Tanaka M, Masudam N, Sugisakim K, Yamamatom M, Yamakawa M, Nagai J, and Nakashima K (1989). Primary structure of chicken pituitary prolactin deduced from the cDNA sequence. Conserved and specific amino acid residues in the domains of the prolactins. The Journal of Biological Chemistry, 264: 5535-5539. Available at: https://www.jbc.org/content/264/10/5535.long

Wawro K, Wilkiewicz-Wawro E, Kleczek K, and Brzozowski W (2004). Slaughter value and meat quality of Muscovy ducks, Pekin ducks and their crossbreeds. Archiv fur Tierzucht, 47(3): 287-299. DOI: https://www.doi.org/10.5194/aab-47-287-2004

Xu ZQ, He J, Ji CL, Zhang Y, Nie QH, Zhang DX, and Zhang XQ (2015). Polymorphisms in the 5'-flanking regions of the GH, PRL, and Pit-1 genes with Muscovy duck egg production. Journal of Animal Science, 93: 28-34. DOI: https://www.doi.org/10.2527/jas.2014-8071

Yadav SK, Maurya SK, Yadav AK, Kumar A, and Yadav K (2018). Study of prolactin receptor gene (PRLR5) polymorphisms and its association with egg production in Kadaknath hens. Indian Journal of Animal Research, 52(8): 1232-1235. DOI: https://www.doi.org/10.18805/ijar.v0iOF.8001

Yurnalis A, Kamsa Z, and Putra DE (2019). Polymorphism of prolactine genes and its association with body weight in Bayang ducks, local duck from West Sumatera, Indonesia. International Conference on Animal Production for Food Sustainability. IOP Conf. Series: Earth and Environmental Science, 287: 012009. DOI: https://www.doi.org/10.1088/17551315/287/1/02009

Zeng T, Chen L, Du X, Lai SJ, Huang SP, Liu YL, and Lu LZ (2016). Association analysis between feed efficiency studies and expression of hypothalamic neuropeptide genes in laying ducks. Animal genetics, 47(5): 606-609. DOI: https://www.doi.org/10.1111/age.12457 